University of Wollongong

Research Online

Faculty of Business - Papers (Archive)

Faculty of Business and Law

$1-1-2011$

Broker recommendations and Australian small-cap equity fund management

Carole Comerton-Forde

University of Sydney

David R. Gallagher

University of Technology Sydney

Joyce Lai

Morgan Stanley

Terry S. Walter

University of Technology Sydney, twalter@uow.edu.au

Follow this and additional works at: https://ro.uow.edu.au/buspapers

Part of the Business Commons

Research Online is the open access institutional repository for the University of Wollongong. For further information contact the UOW Library: research-pubs@uow.edu.au 


\title{
Broker recommendations and Australian small-cap equity fund management
}

\author{
Abstract \\ This study examines whether the abnormal performance of active Australian small-cap equity fund \\ managers is associated with broker recommendations. Our evidence supports the investment value of \\ broker recommendations, showing significant abnormal returns (ARs) both pre- and post-broker \\ recommendations. We find that when a factor-mimicking portfolio based on broker recommendations is \\ added to a Carhart (1997) model, annual alphas are reduced by 48 basis points. Using transaction-level \\ data, buy trades following broker recommendations earn significant cumulative ARs of 1.56 per cent after \\ 60 days. Overall, we find that broker recommendations account for an economically significant \\ component of alphas. \\ Disciplines \\ Business \\ Publication Details \\ Comerton-Forde, C., Gallagher, D. R., Lai, J. \& Walter, T. (2011). Broker recommendations and Australian \\ small-cap equity fund management. Accounting and Finance, 51 (4), 893-922.
}

This journal article is available at Research Online: https://ro.uow.edu.au/buspapers/1191 


\title{
Broker Recommendations and Australian Small-Cap Equity Fund Management
}

\author{
Carole Comerton-Forde ${ }^{a}$, David R. Gallagher ${ }^{\mathrm{b}}$, Joyce Lai ${ }^{\mathrm{c}}$ and Terry Walter ${ }^{\mathrm{b}}$ \\ ${ }^{a}$ Discipline of Finance, The University of Sydney \\ ${ }^{\mathbf{b}}$ School of Finance and Economics, University of Technology, Sydney \\ ${ }^{\mathbf{c}}$ Morgan Stanley, Hong Kong
}

\begin{abstract}
This study examines the extent to which the abnormal performance of active Australian small-cap equity fund managers, previously documented by Chen et al. (2010), is associated with broker recommendations. Our empirical evidence supports the investment value of broker recommendations, showing statistically significant cumulative abnormal returns both pre and post broker recommendation dates. We find that a factor-mimicking portfolio based on broker recommendations results in a 48 basis point reduction in annual alphas estimated from a Carhart (1997) four-factor model (from 58 to 54 basis points a month). Using transaction-level data, buy trades following recommendations earn statistically significant cumulative abnormal returns of 1.56 percent after 60 days. Overall, we find evidence suggesting that broker recommendations play an important role in the investment decisions of small-cap fund managers, and these account for an economically significant component of the monthly alphas.
\end{abstract}

\section{JEL Classification:}

Keywords: Active Small-Cap Fund Management; Broker Recommendations; Alpha

Corresponding Author: Terry Walter (terry.walter@uts.edu.au) 


\section{Introduction}

The recent abnormal performance by Australian small-cap equity fund managers (see Chen et al. (2010), Gallagher and Looi (2006)) prompts the question of whether small-cap managers are genuinely well-informed. ${ }^{1}$ Our paper is primarily empirical, though it has its theoretical motivation in information economics. Active equity fund managers are known to conduct in-house research and establish relationships with company management in attempts to beat the benchmark index. These research and relationship-building activities are costly, and potentially give small-cap managers an information advantage over other investors. Grossman and Stiglitz (1980) argue that markets prices must be sufficiently noisy to allow traders and investors who engage in costly information search to recover these costs, or else there is no incentive to become informed. This information advantage might contribute to the significant alphas their portfolios have achieved in recent years (see Chen et al. 2010). In addition to their own research, fund managers also rely on their broker panels for timely access to valuable information and trade execution services. Thus,, their observed alphas may be partly derived by trading on the basis of broker recommendations, which are also known to possess information content. Brokers are an important information gateway that enable fund managers to trade on other opportunities as a means of exploiting valuable private information in a timely manner. Accordingly, this study explores whether smallcap equity fund outperformance is correlated with managers following the recommendations of brokers, as well as the extent to which broker recommendations influence the investment decisions of Australian funds trading in small cap stocks. Our research has important practical implications for active portfolio management because it is very much in the spirit of the alpha capture hedge fund strategies developed by Marshall Wace in 2002 (the Trade Optimized Portfolio System) which uses computer algorithms for analysing and evaluating brokers' best tips.

This study makes a number of contributions to the empirical literature. First, we extend the work of Chan et al. (2006), through the use of robust methods to compute abnormal returns, with a focus on short-term horizons for returns around broker recommendation dates. This is in light of findings by Kothari and Warner (2006) that misspecification is common in long-horizon event studies. Furthermore, we use a large and representative sample of broker recommendations to confirm the findings of Chan et al. (2006) that broker recommendations possess information content within the Australian market. Second, we provide a link between broker recommendations and the value derived by small-cap equity fund managers. There exists an extensive literature on

\footnotetext{
\# This research was funded through an Australian Research Council Discovery Grant (DP0665826). We thank an anonymous referee, as well as comments from participants at the 2009 Financial Management Association Conference and the 2009 Asian Finance Association Conference. We especially acknowledge the comments of the referees at those conferences, Jay Wang and Anup Basu respectively, and Adrian Lee for research assistance. We also acknowledge Philip Brown who supplied the monthly Fama-French factors. ${ }^{1}$ Chen et al. (2010) find evidence of small-cap managers' stock selection ability with risk-adjusted abnormal returns of between 59.6 and 76.1 basis points per month. Furthermore, Gallagher and Looi (2006) find evidence that fund managers are better at exploiting potential mispricing for the most liquid of small-cap stocks (ranked 101st to 150th in market capitalisation) on the Australian Stock Exchange (ASX).
} 
the investment value of broker recommendations, including Womack (1996) and Barber et al. (2001). However, no study to our knowledge tests whether information asymmetry is one of the drivers of small-cap equity fund outperformance. We test this by using broker recommendations as a proxy for valuable information, and investigate the extent to which these recommendations affect the investment decisions of small-cap equity fund managers. Third, our research extends the widely adopted four factor Carhart (1997) model applied to mutual funds, using a fifth factor controlling for information asymmetry available from connections to the brokerage industry. To the best of our knowledge, no published paper has extended the Carhart model with a fifth factor, nor included a factor of this specification in measuring risk-adjusted performance.

Initially, performance is analysed through returns-based models using a representative dataset of 34 active institutional Australian small-cap equity funds. We also extend the traditional factor models of Jensen (1968), Fama and French (1992) and Carhart (1997) to incorporate broker recommendations as an additional factor. ${ }^{2}$ This factor model extension confirms that a component of the significant alphas documented in Chen et al. (2010) can be attributed to an investment strategy based on broker recommendations. In addition to returns-based performance models, transaction-based measures are used to determine the extent to which equity fund managers trade in small cap stocks on the basis of recommendation levels. This approach represents a significant improvement to holdings-inferred trades observed over quarterly or monthly intervals (for example, see Chen et al. (2000) for the U.S. and Pinnuck (2003), for Australia). We also use a number of innovative approaches to analyse the transaction-based performance of small-cap equity managers, including their performance sensitivity around recommendation levels, research coverage levels and timing factors.

The findings on returns-based performance models are consistent with those of Chen et al. (2010) in that small-cap equity managers possess stock selection ability. Using a Carhart (1997) model, we show small-cap managers earn economically and statistically significant alphas of 58 basis points a month. Furthermore, the addition of a broker recommendation mimicking factor portfolio to the Carhart (1997) model reduces alpha by 48 basis points per annum (i.e., from 58 to 54 basis points a month), although it continues to be statistically significant. This is important also from an economic perspective, where the average management expenses of small-cap funds are about twice the size of the decay in alpha when we apply a broker mimicking factor. In other words, the alpha generated using the five-factor model which accounts for a proxy of information asymmetry represents almost half the annual average management expense ratio for the funds.

The remainder of the study is structured as follows. Section 2 provides a brief review of literature and the hypotheses. Section 3 outlines the data used in this study, while Section 4

\footnotetext{
2 Chan and Faff (2003) test the importance of liquidity, in addition to factors for the market return, size, book-to-market and momentum, in explaining Australian equity returns. They find that stocks with lower liquidity have higher returns.
} 
provides an outline of the research design, and this is followed by the empirical results as well as a number of robustness tests in Section 5. Section 6 concludes.

\section{Background and Hypotheses}

Brokerage houses expend considerable resources to collect, analyse and publish information on stocks to investors. Grosman and Stiglitz's (1980) Sell-side analysts are also known to develop strong relationships with the management of the companies they cover. In spite of regulation which prohibits the selective disclosure of material information by sell-side analysts, ${ }^{3}$ research analysts are often perceived to have an information advantage over other investors given their perceived proximity and access to company management. This may be attributed to either their superior ability in analysing and processing public information, or by acquiring private information before other market participants. The significant stock price reaction upon the announcement of a recommendation is interpreted as recommendations having information content.

Broker research coverage has been documented to explain information asymmetries. Arbel et al. (1983) first discovered a 'neglected firm effect' where firms with minimal research coverage experience higher returns. These returns persist after controlling for stock size, which is important given that smaller firms tend to have lower analyst coverage. Dhiensiri and Sayrak (2005) find that the value of a recommendation revision is inversely related to the number of analysts following a firm, which is also similarly supported by Kelly and Ljungqvist (2007). This notion that stocks with lower research coverage possess a greater degree of information asymmetry, potentially provides opportunities for small-cap equity managers to earn excess returns.

An 'Initiating' recommendation on a stock represents the first coverage of that stock by a broker. Given a lack of prior information, Chan et al. (2006) posit that 'Initiating' recommendations have greater information content and price response upon their announcement. Demiroglu and Ryngaert (2008) find that 'neglected' stocks with no prior research coverage in the past year experience abnormal returns of up to 4.82 percent upon announcement. Although these authors acknowledge their result is partially attributed to an initiation with favourable information content, it suggests an information asymmetry for firms prior to their first analyst coverage. Similarly, Irvine (2003) finds that the incremental price impact of an initiation of coverage is 1.02 percent greater than the price reaction for a recommendation on a stock that is already covered. There is also evidence of this in the Australian market by Chan et al. (2006), which shows that returns on initiating buy (sell) recommendations are significantly greater (less) than zero over the six months following their release.

3 Such regulations include Regulation Fair Disclosure (Regulation FD) in the United States and the Continuous Disclosure requirements in Australia. In addition, the Securities Exchange Commission in 2003 undertook enforcement action with respect to ten investment banks that led to the Global Settlement. The SEC actions were brought with respect to the investment banking entities having improper influence on securities research in the brokerage divisions of these firms. 
In the Chan et al. (2006) study, recommendations are classified as 'Initiating' if a particular broker has not published a recommendation in the past one two or three years ${ }^{4}$, and 'Continuing' if otherwise. Furthermore, 'Virgin' recommendations are a subset of 'Initiating' recommendations and are the first coverage of that stock by any broker. Chan et al. (2006) expect 'Virgin' recommendations to have the greatest information content. However, their finding differs to Irvine (2003), as the share price reactions of 'Virgin' recommendations are not significantly different from 'Continuing' or 'Initiating' recommendations.

The literature generally finds that broker recommendations have investment value. Beneish (1991) and Stickel (1995) find significantly positive (negative) stock price reactions to buy (sell) recommendations. Broker recommendations are also found to have predictive power with respect to stock returns (see Elton et al. (1986), Womack (1996) and Barber et al. (2001)). Australian evidence also indicates that brokers have stock-picking ability (see Aitken et al. (2000)).

The literature has also investigated changes, rather than the absolute level of analyst recommendations, and their impact on stock returns (see Elton et al. (1986) and Womack (1996)). Jegadeesh et al. (2004) find that the quarterly change in consensus recommendation level is also a robust predictor of returns. Research on investment strategies, formed around recommendations, has also documented abnormal returns (Barber et al. (2001)).

There is limited literature on the value of broker recommendations with respect to equity funds. Industry surveys reveal that most funds employ their own in-house analysts to provide private research coverage of stocks. In addition, funds themselves have access to company management in the same way that sell-side research analysts do. The ability of equity fund managers to conduct their own private research, and possibly obtain information from company management, suggests that fund managers may be informed. However, a study by Brown et al. (2008) examines the extent of recommendation motivated trades and finds that mutual funds 'herd' into (out of) stocks with consensus upgrades (downgrades). Similarly, Chan et al. (2005) finds that the extent of such herding is greater with increased information uncertainty, which is proxied by the dispersion in analyst forecasts. These two studies provide evidence that mutual funds rely heavily on the public information provided through broker recommendations.

An alternative view proposed by Irvine et al. (2007) is that sell-side analysts 'tip' their institutional clients prior to recommendation release. Their joint finding that (i) institutional trading increases significantly in the days prior to recommendation date and that (ii) these trades earn positive abnormal returns provides some support for the tipping hypothesis. However, given the gap in the literature linking broker recommendations and equity funds, it is appropriate to test how public information, such as broker recommendations, are used in the investment decisions of Australian small-cap funds, in light of recent evidence demonstrating outperformance.

In this study, we empirically investigate five hypotheses:

\footnotetext{
${ }^{4}$ Chan et al. (2006) use three different periods of time to determine if a recommendation is initiating, namely whether there was a recommendation by the same broker in the previous one, two or three years.
} 


\section{Hypothesis 1}

Broker recommendations are short-term predictors of stock returns and possess information content. Initiating recommendations have greater information content and share price reactions upon announcement than continuing recommendations.

\section{Hypothesis 2}

Small-cap equity managers mimic broker recommendations in their investment decisions; hence the alpha earned by these managers can be (partly) attributed to the information contained in recommendations.

\section{Hypothesis 3}

Active Australian small-cap equity managers trade on the basis of recommendation levels and subsequently earn significant abnormal returns on these trades.

\section{Hypothesis 4}

Active Australian small-cap equity managers build up positions in stocks with upcoming recommendations and earn subsequent abnormal returns from these positions.

\section{Hypothesis 5}

Research coverage levels are inversely related to the level of abnormal returns earned from smallcap equity manager trades.

\section{Data}

Small-cap funds in Australia generally target stocks that are constituents of the S\&P/ASX300 Index (hereafter ASX 300) but lie outside of the S\&P/ASX 100 Index (hereafter ASX 100). These stocks comprise the S\&P/ASX Small Ordinaries Index (hereafter Small Ordinaries). Based on ASSIRT estimates, the total funds under management of the small-cap funds industry at 30 April 2007 is approximately $\mathrm{A} \$ 4,561$ million, or approximately seven percent of the total Australian equity market capitalisation.

In the period 1994-2008 broker coverage has increased over time. The total number of brokers in the market has increased, as too has the mean number of brokers following a Small Ordinaries index stock, which increased from 2.54 in 1994 to 5.13 in 2008. A total of 650 stocks were at some stage included in the small ordinaries index during our sample period. The average number of unique brokers that issued a recommendation on these 650 stocks at some stage during the 15 year period was 7.76 . Small-cap stocks are generally associated with lower research analyst coverage levels than large-caps stocks.

Broker recommendations are sourced from the IBES database. We include stocks ranked between 101st and 300th in market capitalisation between November 1993 and December 2008 in our recommendation database, resulting in a sample of 801 'small caps'. Of these, 762 unique stocks had recommendations in IBES, with a total of 21,231 unique recommendations. This forms the full recommendation sample, in which a total of 64 unique brokers provide recommendations. 
Most brokers use an expanded classification system with recommendations such as underweight, overweight, underperform and outperform. For consistency, the IBES database converts these to a 5-point classification system, which we use in this study. The categories are Strong Buy, Buy, Hold, Underperform and Sell.

Consistent with the literature, considerable asymmetry exists in the number of buy and sell recommendations, with Strong Buys and Buys combined outnumbering Sells and Underperforms by a factor of 2.8 in the full sample. This asymmetry is even greater in Virgin recommendations, where the buy/sell ratio is 4.2. The direction of this bias to recommend stocks as buys is in line with economic incentives that exist for analysts to issue favourable recommendations. It is also consistent with the notion that a self-selection bias exists, where firms tend to initiate coverage on firms with favourable prospects as a mechanism to generate trading commissions.

The Mercer Manager Performance Analytics (Mercer) database includes the monthly returns of 40 active Australian small-cap equity funds, on a pre-expense basis. Following Chen et al. (2010), each fund in our sample is required to have a minimum of 12 consecutive monthly returns between January 1991 and March 2004 to allow model estimation. The resulting subsample of 34 active small-cap funds has consecutive returns that range from 14 to 158 months.

We also use the Portfolio Analytics (PA) database which includes month-end portfolio holdings and daily transactions of a subset of the small-cap equity fund managers. The PA database was constructed using an 'invitation' approach to the largest equity investment managers (on the basis of funds under management) in Australia. Each manager was requested to provide on a confidential basis, information on their largest pooled active Australian equity funds that were open to institutional investors.

The PA database includes month-end portfolio holdings of 13 active Australian small-cap equity funds, which are managed by 11 separate managers. The holdings are from March 1995 to June 2004. This represents a sample of 38,261 individual holdings of stocks by the small-cap fund managers. As at the end of the sample period in 2004, the PA funds had a total of A $\$ 0.76$ billion in funds under management. Hence the PA database accounts for approximately 16.7 percent of the entire small-cap fund universe (by funds under management). Furthermore, the mean monthly fund size by net asset value (NAV) throughout the sample period is A $\$ 78.5$ million. The daily transaction data for the small-cap fund managers include the aggregate daily trades of 12 active Australian small-cap equity funds, which are managed by ten unique fund managers. On a transaction level, the full sample is made up of 43,700 aggregated daily trades over a seven-year period spanning February 1997 to June 2004.

Rather than analysing each trade separately, we follow Chan and Lakonishok (1995) and group individual trades into trade packages.

$<<$ INSERT TABLE 1 ABOUT HERE $>>$ 
Table 1 provides summary statistics for the trade packages formed from the daily transactions of the small-cap fund managers in the PA database. Of the 43,700 aggregated daily trades comprising the full sample, 15,060 trade packages are formed using the five-day definition. Of these, buy packages outnumber sell packages, with 8,525 buy packages and compared to 6,535 sell packages. Within the full sample, 52 (51) percent of the buy (sell) packages are executed within a single day and approximately 76 percent of all trade packages (i.e., both buy and sell trades) are executed within four days.

To examine the behaviour and performance of small-cap fund managers around broker recommendations, we form a recommendation subsample of trade packages, based on stocks with data from our recommendations file. In forming the sub-sample, we require stocks to be continuously traded over the past year, as momentum characteristics are required to calculate DGTW-adjusted daily abnormal returns around trade packages. This results in a 'recommendation subsample' of 2,800 trade packages, 1,572 buys and 1,228 sells. The sample size is considerably smaller than the full sample; hence we also calculated descriptive statistics for this set to ensure no selection bias has occurred. The results are quantitatively similar to those in Table 1, though in general the value of the packages for this reduced set of recommendations is somewhat larger than those for the full sample. ${ }^{5}$

In addition to analyst recommendations and fund manager data, stock-specific information such as price, dividend and capitalisation change data are needed to calculate returns. For this, ASX daily price data are sourced from the Securities Industry Research Centre of Asia-Pacific (SIRCA). These include daily opening and closing prices, daily high and low prices and also daily trading volumes and values. In addition, a daily dilution factor is included for each stock to take into account changes in shares outstanding due to events such as dividends, rights issues or stock splits. Accounting information such as book-to-market ratios for multi-factor models are sourced from the Aspect Financial database.

\section{Research Design}

In this section, we outline our research design used to test whether broker recommendations have information content and investment value, as proposed in Hypothesis 1. After classifying recommendations by level and type, we conduct an event study to investigate the share price reaction and the presence of statistically significant abnormal returns around the recommendation date. For robustness, two approaches are used to compute abnormal returns - the traditional market model, as well as a control-firm approach first developed by Daniel et al. (1997).

\footnotetext{
${ }^{5}$ These results are available from the corresponding author on request.
} 


\subsection{Classifying Recommendations by Level and Type}

Initially, recommendations are grouped into three categories by level. These are (i) Strong Buys or Buys, (ii) Holds, and (iii) Underperform or Sell. The IBES classification system is used to group recommendations by level.

Following this, recommendations are classified according to their Type, as per Chan et al. (2006). An Initiating recommendation is the first recommendation made on a stock by a particular broker, where other brokers currently cover the stock. A Virgin recommendation is the first recommendation made on a stock by any broker. Thus, Virgin recommendations are a subset of Initiating recommendations. As the IBES database commences in 1993 for Australian stocks, we use 1993 as a 'holdout' year and classify Virgin or Initiating stocks if no prior recommendations were issued during that year. The remaining recommendations are classified as Continuing.

\subsection{Abnormal Returns around Recommendation Date - Market Model}

An event study methodology with a short-horizon window is used to compute the abnormal returns around recommendation date. While Chan et al. (2006) focus on six-month returns following recommendation, we focus on the abnormal returns in the two weeks around a stock's recommendation date. We estimate the familiar market model during a 180 day 'estimation period' prior to each recommendation date, using the Small Ordinaries index values to calculate the market return. Abnormal returns (ARs) on a stock for the ten days around a recommendation date are computed as the difference between the actual return and the expected return as predicted by the market model. ${ }^{6}$ Based on the entire sample of recommendations, mean daily ARs are computed by averaging across recommendations in the sample and the ARs are then summed to form cumulative abnormal returns (CARs).

\subsection{DGTW-Adjusted Abnormal Returns}

A DGTW control-firm approach to benchmark stock returns is adopted as an additional robustness check. This approach is motivated by the characteristics of the underlying stocks held in fund portfolios examined in Daniel et al. (1997). These include well-known market anomalies such as size, book-to-market and momentum. Although the DGTW method was developed to measure mutual fund performance, this benchmarking approach can also be applied to computing abnormal returns on individual stocks.

To compute abnormal returns around recommendation date, we use daily DGTW-adjusted alphas constructed by Fong et al. (2008) based on the Pinnuck (2003) approach. The Pinnuck (2003) approach modifies the Daniel et al. (1997) approach for an Australian context and is

\footnotetext{
${ }^{6}$ Following the event study approach suggested by MacKinlay (1997), we include a separation between the estimation $(\mathrm{t}=-200$ to $\mathrm{t}=-20)$ and event windows $(\mathrm{t}=-10$ to $\mathrm{t}=+10)$, which prevents event-related activity in the stock price from influencing the estimated market model parameters.
} 
constructed on a stock universe consistent with our benchmark specification. The daily DGTWadjusted alphas can be expressed algebraically as:

$$
A R_{i, t}=r_{i, t}-r_{t}^{D G T W(i)}
$$

where $A R_{i, t}$ is the abnormal return on the underlying stock of recommendation $i$ at time $t, r_{i, t}$ is the actual return on underlying stock of recommendation $i$ on day $t$ and $r_{t}^{D G T W(i)}$ is the return of a characteristic matched benchmark portfolio assigned to the underlying stock of recommendation $i$ across the characteristics of size, book-to-market and momentum.

Following this, the mean abnormal return is computed based on daily abnormal returns averaged across all recommendations in the sample and cumulative abnormal returns (CARs) around recommendation date are calculated.

\subsection{Returns-Based Performance Measures}

Returns-based performance measures are used to determine whether small-cap equity managers have the ability to outperform passively selected benchmark portfolios. The literature has proposed a number of factor models in risk-adjusting the returns of mutual funds, including the approaches advocated by Jensen (1968), Fama and French (1992) and Carhart (1997). The purpose of these multi-factor models is to control for strategies that are known to generate alpha in capital markets. The reliance on multi-factor risk models is therefore an attempt to measure the true value of services rendered by active fund managers, and thereby account for alpha that is otherwise delivered from well-known risk factors shown to explain stock returns in the cross-section. Studies by Chen and Knez (1996) and Admati and Pfleiderer (1997) argue the importance of accurately benchmarking performance in the compensation of investment managers. Indeed, in the Australian literature, asset pricing tests by Chan and Faff (2003) and Gharghori, Chan and Faff (2007) are recent examples that propose extensions to the Fama-French three-factor model with respect to liquidity (proxied by trade volume) and default risk, respectively.

A number of commonly used single and multi-factor models are employed in our study, namely the Jensen approach, Fama-French, Carhart, and our new model that further accounts for asymmetries related to broker recommendations (a test of Hypothesis 2). Further details of these models are outlined in Chen et al. (2010). An innovation of this study is that it is the first to account for broker recommendations as a potential source of alpha generation by active small-cap equity funds.

In constructing a broker recommendation factor $B M S$ or 'Buy minus Sell', mimicking portfolios are formed on a monthly basis, which take a long position in stocks with newly issued Strong Buy or Buy recommendations during the month, and a short position in stocks with newly issued Underperform or Sell recommendations in the month. 
In addition, $B M S$ is formed from a recommendation sample whose stocks were members of the Small Ordinaries Index in the month of recommendation. This is to ensure that only pure 'small-cap' stocks which fall under the investment mandate of small-cap managers are included.

In any month, it is possible for several brokers to issue conflicting recommendation levels on a stock. It is also possible for a single broker to revise the recommendation level on a stock from a buy to a sell and vice versa. For stocks which had 'conflicting' recommendations, the consensus recommendation for that month is used to classify the stock. Within our sample of 4,770 buy or sell recommendation/months, we identified only 160 instances of 'conflicting' recommendation/months and applied the monthly consensus recommendation level to these cases.

The five-factor model used in this study is thus specified as follows;

$$
r_{i, t}=a_{i}+b_{i S O} r_{m, t}+b_{i H M L_{t}} H M L_{t}+b_{i S M B} S M B_{t}+b_{i P R 1 Y R} P R I Y R_{t}+b_{i B M S} B M S_{t}+e_{i, t}
$$

The HML, SMB, and PRIYR factors are constructed as per the Carhart (1997) four-factor model. $B M S$ represents a 'Buy minus Sell' broker recommendation factor, and $b_{i B M S}$ is its corresponding loading coefficient.

\subsection{Justification of Market Benchmarks Specified}

Specification of an appropriate benchmark and model is extremely important, in light of recent studies which suggest that inferences of abnormal performance are highly sensitive to choice of benchmarks and models, such as Kothari and Warner (2001) ${ }^{7}$. In particular, the chosen market portfolio should adequately reflect the investment styles of the fund managers in the sample. Typically, small-cap fund managers are benchmarked against the Small Ordinaries index. Indeed, an analysis of their holdings shows that over 70 percent of funds are invested in the Small Ordinaries Index constituent stocks. Further, Lehmann and Modest (1987) also stress the importance of a consistent approach when constructing benchmark factors. The broker recommendation $B M S$ factor has been constructed using Small Ordinaries stocks, as this appropriately reflects the underlying stocks small-cap equity managers invest in. Based on both an analysis of the holdings and the way $B M S$ was constructed, the Small Ordinaries Index is initially used as the market risk factor in returns-based performance evaluation models.

However, an issue that arises is that the Carhart (1997) mimicking factors that we have access to are constructed from stocks within the All Ordinaries Index. To incorporate the use of a wider benchmark and to ensure consistency in benchmark construction, the All Ordinaries Index is also used as a robustness test. The holdings data also shows approximately 13 percent of holdings by value are micro-caps and approximately 4 percent of holdings are large-cap stocks in the ASX 100. For this reason, we also create a customised 'Balanced Index' which accurately reflects the proportionate holdings of small-cap equity managers in the sample. The Balanced Index is

\footnotetext{
${ }^{7}$ See also Lehmann and Modest (1987) and Grinblatt and Titman (1993).
} 
constructed using the weighted returns on the ASX 100, Small Ordinaries and Micro-cap stocks (defined as stocks outside of the ASX 300 but within the All Ordinaries indices) with weights of 4/90, 73/90 and 13/90 respectively.

In summary, three key market benchmark specifications are used;

(1) Small Ordinaries Index

(2) All Ordinaries Index

(3) A Self-constructed Balanced Index

\subsection{Broker Recommendations and Small-Cap Manager Trades}

Previous studies have examined fund manager trades by focussing on trades inferred from quarterly or monthly portfolio holdings. However, as pointed out by Gallagher and Looi (2006), this approach fails to capture trading activity during the month. Furthermore, Chen et al. (2000) argue that trades are more likely to signal private information over the passive decision of holding a stock.

Thus, we use a refined level of data, the daily transactions of small-cap equity managers to test Hypothesis 3 that broker recommendations influence fund manager trades, as well as Hypothesis 4 that small-cap managers are informed and build up positions in stocks with an upcoming recommendation. As mentioned above, consistent with the approach of previous smallcap equity fund studies, such as Gallagher and Looi (2006), Comerton-Forde et al. (2006) and Chen et al. (2010), trades are grouped based on the trade package methodology of Chan and Lakonishok (1995). This is motivated by the fact that fund managers tend to split up large trades to minimise transactions costs through price impact, and to disguise the execution of their trades.

\subsubsection{Trades on the Basis of Recommendation Level}

Under the assumption that there is information content in broker recommendations, we propose in Hypothesis 3 that broker recommendations influence the trades of small-cap equity fund managers in two ways. First, small-cap equity managers trade on the basis of recommendation levels. That is, managers should be more likely to execute a buy trade on stocks with a Buy recommendation or execute a sell trade on stocks with a Sell recommendation. Second, we expect significant abnormal returns to be earned on trades in which a recommendation direction is followed.

To test the extent that small-cap managers trade on the basis of recommendation levels, a database of trade packages which have taken place around a recommendation date is constructed. A trade which had a Strong Buy or Buy (hereafter buy), or an Underperform or Sell (hereafter sell) recommendation in the same month is included in this database. Following this, we partition trade packages on the basis of recommendation level and trade type.

Using the holdings data from the PA database, we further split the full sample based on whether a fund manager had an 'existing position' in the stock when the trade occurred, or whether 
the trade package represented a 'new position' in the stock for a particular fund manager. This is motivated by the idea that managers are more likely to rely on the information content of broker recommendations if they do not have a prior position in the stock.

\subsubsection{Returns around Trade Packages}

Following the partitioning above, we examine the abnormal returns earned on trades which have followed the recommendation direction using the DGTW approach outlined in section 4.3. First, daily DGTW-adjusted abnormal returns are computed in the 60 days before and after the trade package date. The mean daily DGTW-adjusted ARs and the CARs are then calculated for the sample.

\subsubsection{The Information Advantage of Small-Cap Fund Managers}

If recommendations possess information content and if small-cap fund managers are informed as proposed in Hypothesis 4, then we expect to observe trading activity prior to the release of a recommendation. That is, we expect fund managers to have built up positions in stocks where information is due to be released to investors through a recommendation. We also expect that small-cap fund managers earn significant abnormal returns from these positions. Again, we use the trade package methodology of Chan and Lakonishok (1995).

First, instances of managers taking a position prior to recommendation release are identified. Accordingly, a trade package is flagged if the last day of the package occurs in a 10-day period prior to either a Buy or Sell recommendation. Hold recommendations are omitted from this analysis, given the expectation that they do not contain the same level of information as a Buy or Sell recommendation. We initially define a 10-day period as an indication of managers taking a prior position, however other time periods are also used in robustness checks.

After identifying instances of prior positions by small-cap equity managers, a number of trade-related metrics are constructed to analyse the relative magnitude of these trade packages. This is to ensure that small-cap fund managers take substantial positions in stocks with an upcoming recommendation.

\section{Transaction weight}

Within the sample, the small-cap equity funds vary substantially in Net Asset Value (NAV), which has implications on the size of the trades executed. Hence it is more meaningful to examine the relative weight of the trade as a proportion of NAV rather than the absolute value of the trade package. The transaction weight is defined as;

$$
\text { TransactionWeight }_{i j t}=\frac{\text { TradePackageValue }_{i j t}}{N A V_{j t}}
$$

where Trade Package Value $i j t$ is the dollar value of the trade package $i$ made by fund manager $j$ in month $t$, and $N A V_{j t}$ is the net asset value of fund manager $j$ during month $t$. 


\section{Relative Position - Prior and Post Trade}

Fund managers are likely to have existing positions in the stocks in which they trade. For this reason, we are also interested in the relative weight of the overall position in a stock both prior to and following a trade, rather than the weight of the trade package alone. The relative weight of the overall position, both prior to trade and post trade, can be defined as;

$$
\begin{aligned}
& \text { RelativePosition }(\text { Prior })_{i j t}=\frac{\text { HoldingValue }_{i j t-1}}{N A V j t}
\end{aligned}
$$

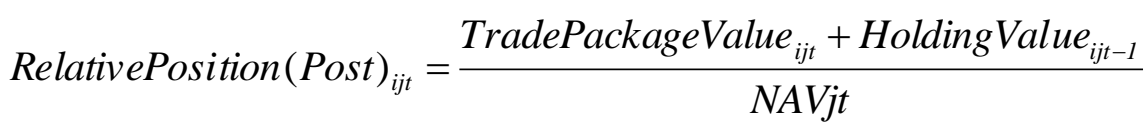

where Trade Package Value $i j t$ is defined as in Equation (3) and Holding Value ijt-1 $_{\text {in }}$ is the value of fund manager $j$ 's holding in the stock underlying trade package $i$ during month $t-1$, given that holdings in the PA database are month-end values.

\section{Overweight Position}

Position weights in a stock may also vary across different stocks, depending on their market capitalisation. For instance, it is expected that positions will be greater in smaller stocks. Hence we also examine the size of a trade package in the context of a stock's weight in the index. We define an overweight (relative to the index) metric as;

$$
\text { Overweight } \left._{i j t}=\text { RelativePosition }_{(\text {Post }}\right)_{i j t}-\text { Weight }_{i t X S O}
$$

where Relative Position(Post $)_{i j t}$ is as per Equation (5), and Weight $t_{i t X S O}$ is the weight of a stock within the Small Ordinaries Index in the corresponding month $t$.

After analysing a number of trade-related metrics, we compute mean daily DGTWadjusted abnormal returns around each prior position trade and average these across the $N$ trade packages in which a prior position was taken, rather than the entire sample. We also compute CARs for the 30- and 60-day periods, again using the last day of a trade package as the reference date.

\subsection{Impact of Coverage Levels on Transaction-Based Performance}

In this section, we outline our approach in testing the information advantage of small-cap equity managers by examining research coverage levels in conjunction with transaction-based performance measures. This is motivated by the 'neglected firm effect' first documented by Arbel et al. (1983) and more recently by Irvine (2003).

If small-cap equity managers are genuinely informed, then we would expect coverage levels to be inversely related with the abnormal returns earned from their trades, as proposed in Hypothesis 5. This is based on the notion that managers are better able to exploit information asymmetry and potential mispricing in stocks with less publicly available information.

Motivated by the approach of Dhiensiri and Sayrak (2005), we initially define sell-side research coverage levels for all the underlying stocks of the trade packages of small-cap funds. 
Based on the recommendations sample, the frequency of issued recommendations varies between different brokers. However, as suggested by Kecskes and Womack (2007), an analyst will at least provide a yearly earnings forecast for the stocks they cover. Given this, we define the 'coverage level' as the total number of brokers issuing a recommendation on a stock within the same year.

Following this, we analyse the performance of trade packages with a split around coverage levels. We use the trade packaging methodology and methods for computing mean daily and cumulative abnormal returns (CARs), consistent with the approach detailed above.

\section{Empirical Results}

\subsection{Value of Brokers' Recommendations}

Table 2 presents the cumulative abnormal returns (CARs) around recommendation date based on a market model approach. All Continuing recommendations earn statistically significant postrecommendation CARs that are consistent with the direction of their forecast, regardless of recommendation level (assuming that a hold recommendation is a disappointment). Initiating and Virgin recommendations are expected to contain greater information content, given there is limited prior information on a stock. Thus a greater price reaction is expected, as proposed in Hypothesis 1. Consistent with this, Initiating hold and underperform/sell recommendations are more negative in the period following the recommendation than those of the Continuing group. Virgin recommendations are however entirely inconsistent with expectations. Virgin buy recommendations have CARs after 10 days of $-1.55 \%$, while the hold and underperform groups have positive, albeit insignificant, returns. Interestingly, there is some evidence of statistically significant negative returns prior to Initiating and Continuing sell recommendation's release, with CARs in the 10 days before the recommendation date of $-0.97 \%$ and $-1.59 \%$ respectively. This finding supports the notion of sell side analysts 'tipping' institutional clients, consistent with Irvine et al. (2007). Overall, our findings based on the market model approach are consistent with those of a previous Australian study by Chan et al. (2006).

\section{<<INSERT TABLE 2 ABOUT HERE >>}

As a robustness check, cumulative abnormal returns around recommendation date are also computed based on DGTW-adjusted daily alphas. These results are very similar to those for the market model, hence they are not reported in detail. ${ }^{8}$ The minor differences are that the negative CARs in the period after the Strong Buy/Buy Virgin recommendations are less significantly

\footnotetext{
${ }^{8}$ These results are available from the corresponding author on request.
} 
negative under the DGTW approach, while some Initiating Strong Buy or Buy recommendations have significantly positive CARs (at the 5 percent level) in the period after the recommendation. ${ }^{9}$

\subsection{Returns-Based Performance Measures}

Single and multi-factor models are used to evaluate small-cap fund manager performance. Each model involves a regression of monthly pre-expense returns of a fund in excess of the monthly riskfree rate against one or more factors. Table 3 reports the results of a number of returns-based performance evaluation models. The magnitude of Jensen's alpha provides an estimate of the level of fund manager skill with respect to stock selection ability after controlling for market risk. Panel A indicates that small-cap equity funds outperform the Small Ordinaries Index by 82 basis points a month, or 9.8 percent annually. In addition, the beta on the market factor indicates that small-cap fund manager returns are highly sensitive to the Small Ordinaries Index. This is not surprising, given that fund managers hold diversified portfolios of stocks, the majority of which are constituents of the Small Ordinaries.

\section{$<<$ INSERT TABLE 3 ABOUT HERE >>}

The results from the Fama-French (1992) model in Panel B and the Carhart (1997) model in Panel $\mathrm{C}$ show that the coefficient on the SMB 'small minus big' size factor is significantly positive, indicating the presence of a small-firm return anomaly, which partly explains the alphas reported in Panel A. Taken together, the SMB and the HML factors (i.e., the Fama-French factors) cause small-cap equity manager returns to drop from 82 to 69 basis points per month. Similarly, Panel $\mathrm{C}$ suggests that small-cap equity managers also adopt momentum strategies, buying (selling) stocks with positive (negative) past six-month returns which also contributes to alphas earned.

After controlling for the additional factor based on the Carhart (1997) four-factor model (i.e., momentum), alpha drops by 11 basis points to 0.58 percent a month, although it remains economically (i.e., 7.0\% per annum) and statistically significant. Our results are consistent with Chen et al. (2009), indicating a pronounced level of stock selection ability amongst small-cap equity fund managers, even after controlling for market anomalies such as size, book-to-market ratio and momentum.

Panel D presents results for a five-factor model where the $B M S$ broker recommendation factor is introduced. Overall, the findings in Panel D confirm Hypothesis 2, i.e., broker recommendations play a role in the investment decisions of small-cap equity managers and contribute to their alphas. The excess return of 58 basis points per month in the Carhart (1997) model is reduced to 54 basis points per month when the $B M S$ factor is added.

\footnotetext{
$9 \mathrm{We}$ also estimated the statistical significance of the results presented in Table 2 recognising that the standard errors might be biased due to clustering, as suggested by Petersen (2009). Our statistical tests are essentially identical under either approach.
} 
The loading coefficient on the Small Ordinaries market factor is reduced from 0.8781 to 0.8132 with the introduction of the $B M S$ factor. This can be explained by the correlation that exists between the $B M S$ factor and the Small Ordinaries market factor ${ }^{10}$. The addition of the $B M S$ factor also causes an increase in the coefficient on the size, book-to-market and momentum factor in Panel C. ${ }^{11}$

\subsection{Transactions-Based Performance Measures}

We now turn to an analysis of fund manager data at the trade level to ascertain the impact of broker recommendations on the trading behaviour and performance of small-cap equity managers. Based on Hypothesis 3, it is expected that small-cap equity managers trade on the basis of broker recommendations. That is, managers should be more likely to execute a buy trade on stocks with a Buy recommendation or execute a sell on stocks with a Sell recommendation.

Table 4 (Panel A) presents the results on transaction-based performance measures, partitioned on the basis of recommendation levels. Consistent with Hypothesis 3, an examination of the CARs reveals that small-cap fund managers earn highly significant CARs on purchases where the underlying stock had a buy recommendation. For example, a buy trade package on a stock with a Buy recommendation earns a cumulative abnormal return of 1.56 percent in the 60-day period following the last day of the buy trade package. The pattern of the CARs for this set of securities suggests that broker Buy recommendations are for stocks with positive momentum, or that fund managers become aware of the recommendation prior to its publication in the IBES database, because the pre-recommendation CARs are a significantly positive $4.37 \%$. In contrast, the stocks sold by small-cap fund managers after a broker Sell recommendation experienced insignificant positive CARs in the order of 0.47 percent in the 60-day period following the last day of the sell trade package.

\section{$<<$ INSERT TABLE 4 ABOUT HERE $>$}

We investigate whether taking a prior position in a stock occurs by examining the daily trades of small-cap equity managers prior to recommendation date.

\footnotetext{
${ }^{10}$ We confirm that multicollinearity is not an issue in the model by conducting further analysis to control for the correlation between BMS and the market factor. Our findings indicate that BMS continues to be statistically significant after accounting for its correlation with the market factor. These results are available from the corresponding author on request.

11 We also estimated the returns-based factor models using a "balanced index" as the market factor. The "balanced index" comprises stocks which reflect the underlying holdings of small-cap equity managers, as detailed in Table 3. Under this benchmark specification essentially the same results detailed in Table 3 are encountered. The various models have high explanatory power, and the alphas are statistically and economically significant across all model specifications. These results are available from the corresponding author on request.
} 
We calculate a number of trade-related metrics to analyse the relative magnitude of the trade packages. The aim is to test whether managers take substantial positions in stocks prior to a recommendation.

Table 5 shows trade packages partitioned by their type (i.e., buy or sell) as well as the recommendation level on the underlying stock. The trade-related metrics are similar across all groups, with the vast majority of trades taking place in stocks for which the manager has an existing position. For example, over 96 percent (98\%) of the sell trade packages following buy (sell) recommendations have an existing position in the stock, indicating that very few of the sell trade packages are indeed short sales. Further, 85 percent (90\%) of the buy trade packages following a Buy (Sell) recommendation have an existing position in the stock, while the mean transaction weight as a proportion of NAV is approximately $0.43(0.32)$ percent. Given that the average number of stocks held by each manager is approximately 46 (and therefore that most of the existing positions will, by definition, be overweight relative to the weights in the small-cap index) and the majority of trade packages already have an existing position in the stock, the magnitude of the trades alone as a proportion of NAV is substantial. Following the trade, the overweight position for buy trades, for which there is a Buy recommendation (1.03), is greater (as expected), than the overweight position for a sell trade following a sell recommendation (0.73). Buy trades following a Buy recommendation are larger, as expected, than buy trades following a Sell recommendation. However, in contrast, managers sell smaller quantities of stock following a Sell recommendation than they do following a Buy recommendation. This finding is perhaps because small-cap fund managers have a smaller proportion of NAV invested in stocks that receive unfavourable Sell recommendations.

\section{$<<$ INSERT TABLE 5 ABOUT HERE >>}

\subsection{Coverage Levels and Transactions-Based Performance}

Table 6 presents the cumulative abnormal returns (CARs) earned around trade packages with a split based on coverage levels. Specifically, Panel A reports the CARs around buy packs for the respective coverage level groups, and Panel B reports CARs for the sell packs. Consistent with Hypothesis 5, sell trades in stocks with lower coverage generated significant CARs post-trade. For the 356 sell trades made in stocks with a zero coverage level, the CARs are a significantly negative (-2.64) percent after 60 days. In contrast, the CARs an insignificant 0.99 percent after 60 days on a sell trade where the stock had more than nine brokers following it. Overall, the CARs follow a decreasing trend as the number of brokers decrease.

This result is consistent with Dhiensiri and Sayrak (2005), who find that recommendations are less informative as the number of analysts following a firm increase. Our findings on sell trades 
support the notion that small-cap equity fund managers exploit the lower levels of information available on stocks with low research coverage, thereby earning statistically significant abnormal returns.

In contrast, and inconsistent with expectations, Panel A reports the performance of buy packs through an analysis of the CARs around the last date of a buy trade package. For buy trades, the magnitude of the CAR following the trade is positively related to broker coverage. Where there are more than nine brokers covering a stock, the post-trade CAR is significantly positive (4.28\%), while buy packs for which there is low analyst coverage have insignificant returns. A possible explanation for this finding is that there needs to be a strong consensus among several brokers in relation to buys, before market participants follow the recommendation, given the propensity for a buy imbalance in broker recommendations. In contrast, sell transactions are more informative when there is low coverage.

\section{$<<$ INSERT TABLE 6 ABOUT HERE $>>$}

\subsection{Robustness Tests}

To strengthen the validity of the findings in this study, a number of robustness tests are conducted. These involve altering the research design to ensure that our results are robust to differences in methodology, as well as alternative econometric techniques.

\subsubsection{Controlling for the Correlation between BMS and the Market Factor}

We control for the correlation between the BMS broker recommendation factor and the market risk factor in the following manner. Firstly, the Small Ordinaries Index is regressed on the BMS factor, and the residuals from this regression, which represent the portion of $B M S$ that is uncorrelated with the Small Ordinaries market factor (which we term $B M S^{*}$ ) are used in a five-factor model in which $B M S^{*}$ is used in place of $B M S$ in Equation (2).

We also repeat the process, substituting the All Ordinaries Index and a Balanced Index in place of the Small Ordinaries Index. The regression results ${ }^{12}$ indicate that across all the two benchmark specifications, the coefficient on the $B M S$ factor continues to be significant. Hence, after controlling for the correlation between $B M S$ and the market factor, broker recommendations continue to play a significant role in the investment decisions of small-cap managers.

\subsubsection{Long-Only Portfolios in Five-Factor Model}

The broker recommendation factor $B M S$ is formed on the assumption that fund managers are equally able to take short and long positions in stocks. However, an analysis of the holdings data reveals that short positions are rare or non-existent. For instance, Saar (2001) observes that funds

\footnotetext{
12 These results are available from the corresponding author on request.
} 
generally do not short sell, to avoid risking unlimited losses if the stock price goes up. Furthermore, the charters of many funds restrict the usage of short sales.

Based on this, we re-construct the $B M S$ factor using long-only portfolios that better reflect the actual portfolio allocation decisions of small-cap funds.

To construct a long-only $B M S$ factor, a long position is taken in newly issued buy recommendations each month. For stocks with both buy and sell recommendations, the consensus recommendation is applied for that month and a long position is taken if its consensus recommendation is a buy. Following this, returns-based factor models are estimated. These results confirm the robustness of our findings, as the significance of the $B M S$ factor and the results as a whole remains unchanged. ${ }^{13}$

\subsubsection{Changing Risk due to the Technology Boom and Bust}

The sample period used in the returns-based performance regressions encompass both the technology boom and its subsequent bust in 2001. As a robustness test, we control for possible differences in the risk and levels of information asymmetry attributable to this event. Given that the bust occurred in 2001, we divide the sample in half to capture the lead up 'boom' period prior to and excluding 2001, as well as its subsequent 'bust' from 2001 onwards. This approach is chosen over a regression with calendar year dummies as it prevents over-specification of the models. The results indicate that the magnitude and significance of alpha is highly sensitive to this event. ${ }^{14}$ Furthermore, the results suggest that small-cap managers invested in the technology boom, with a tilt towards growth stocks prior to 2001, as observed by a statistically significant negative coefficient on the $H M L$ factor. This is observed across all model specifications. They also profited from this, given the statistically significant alpha of 53 basis points per month prior to 2001 from the five-factor model. Interestingly, we observe that the BMS factor is statistically significant prior to the boom, but not after. This suggests that post-2001, small-cap managers were perhaps more cautious and did not rely as much on the information provided by brokers for their investments. Further, alpha is not statistically different to zero in the bust period.

\section{Conclusion}

Chen et al. (2010) find evidence of the stock selection ability of small-cap equity managers, as they earn risk-adjusted abnormal returns of between 60 and 76 basis points per month. The large magnitude of the alphas earned inevitably prompts the question of whether returns can be explained through the information advantage of small-cap funds.

Our study contributes to the literature by jointly exploring the areas of broker recommendations and small-cap equity funds to determine how valuable the recommendations are in the fund management process. Given that the outperformance of these fund managers has been

\footnotetext{
${ }^{13}$ These results are available from the corresponding author on request.
}

14 These results are available from the corresponding author on request. 
confirmed, this study is unique in that it seeks to understand the drivers behind such outperformance, such as the information asymmetry between managers and investors in the market.

Initially, we confirm the findings of Chan et al. (2006) in that broker recommendations possess investment value. We also show that the price reaction around Initiating recommendations is not significantly different from 'Continuing' recommendations. These findings are confirmed using two approaches of estimating abnormal returns, a traditional market model approach and a DGTW-approach motivated by Daniel et al. (1997).

The findings on returns-based performance models are consistent with those of Chen et al. (2010) in that small-cap equity managers possess stock selection ability. Using a Carhart (1997) model, we show small-cap managers earn economically and statistically significant alphas of 58 basis points a month. Furthermore, the addition of a broker recommendation mimicking factor portfolio to the Carhart (1997) model reduces alpha by 48 basis points per annum (i.e., from 58 to 54 basis points a month), although it continues to be statistically significant. We additionally test the robustness of alpha across alternative benchmark specifications of the market factor. Our transaction-based performance measures involve the examination of DGTW-adjusted cumulative abnormal returns (CARs) around trades. We find that small-cap equity managers earn statistically significant abnormal returns on trades that follow broker recommendations. Furthermore, managers have a greater likelihood of trading on the basis of recommendation levels if they do not have an existing position in a stock prior to the trade, presumably due a lack of information and company relationships on these stocks.

Further, we find that the abnormal returns following small-cap equity manager sell trades are inversely related to the number of analysts following a stock, whereas results are reversed for buy trades. This confirms findings in the literature that sell trades are motivated by information and allow managers to exploit mispricing when there is lower coverage levels, whereas buy trades are informative only when there is a strong buy consensus recommendation among several brokers.

Finally, it is known that brokers and fund managers alike may have expertise in a particular industry, which could result in an information advantage over market participants. For example, Boni and Womack (2004) take an industry perspective when analysing broker recommendation value and find that an analysts' industry expertise provides incremental investment value. With this in mind, it would be interesting to take industry expertise into account when examining the impact of broker recommendations on small-cap funds. 


\section{References}

Admati, A., and P. Pfleiderer (1997). Does It All Add Up? Benchmarks and the Compensation of Active Portfolio Managers, Journal of Business, 70(3), 323-350.

Aitken, M., Wong, K., and Muthuswamy, J. (2000). The Impact of Brokers' Recommendations: Australian Evidence. PACAP/FMA conference paper, Melbourne.

Arbel, A., Carvell, S., and Strebel, P. (1983). Giraffes, Institutions And Neglected Firms. Financial Analysts Journal, 39(3), 57-63.

Barber, B., Lehavy, R., McNichols, M., and Trueman, B. (2001). Can Investors Profit from the Prophets? Security Analyst Recommendations and Stock Returns. Journal of Finance, 56(2), 531-563.

Beneish, M. D. (1991). Stock Prices and the Dissemination of Analysts' Recommendation. Journal of Business, 64(3), 393.

Boni, L., and K. Womack (2004). Analysts, Industries and Price Momentum. Working paper, Tuck School of Business.

Brown, N. C., Wei, K. D., and Wermers, R. R. (2008). Analyst Recommendations, Mutual Fund Herding, and Overreaction in Stock Prices. Working Paper.

Carhart, M. M. (1997). On Persistence in Mutual Fund Performance. Journal of Finance, 52(1), 5782.

Chan, H. W. H., Brown, R., and Ho, Y. K. (2006). Initiation of Brokers' Recommendations, Market Predictors and Stock Returns. Journal of Multinational Financial Management, 16(3), 213231.

Chan, H., and R. Faff (2003). An Investigation into the Role of Liquidity in Asset Pricing: Australian Evidence, Pacific-Basin Finance Journal 11, 555-572.

Chan, K., Hwang, C.-Y., and Mian, G. M. (2005). Mutual Fund Herding and Dispersion of Analysts' Earnings Forecasts. Working Paper.

Chan, L. K. C., and Lakonishok, J. (1995). The Behavior of Stock Prices Around Institutional Trades. Journal of Finance, 50(4), 1147-1174.

Chen, C., Comerton-Forde, C., Gallagher, D. R., and Walter, T. S. (2010). Investment Manager Skill in Small-Cap Equities. Australian Journal of Management, forthcoming.

Chen, H.-L., Jegadeesh, N., and Wermers, R. (2000). The Value of Active Mutual Fund Management: An Examination of the Stockholdings and Trades of Fund Managers. Journal of Financial and Quantitative Analysis, 35(3), 343-368.

Chen, Z., and P. Knez (1996). Portfolio Performance Measurement: Theory and Applications, Review of Financial Studies, 9(2), 511-555.

Comerton-Forde, C., Gallagher, D. R., Nahhas, J., and Walter, T. S. (2006). Transaction Costs and Institutional Trading in Small-Cap Equity Funds. Working Paper.

Daniel, K., Grinblatt, M., Titman, S. and Wermers, R. (1997). Measuring Mutual Fund Performance with Characteristic-Based Benchmarks. Journal of Finance, 52, 1035-1058.

Demiroglu, C., and Ryngaert, M. D. (2008). The First Analyst Coverage of Neglected Stocks. Working Paper.

Dhiensiri, N., and Sayrak, A. (2005). The Value Effects of Analysts Coverage Initiations. Working Paper.

Elton, E. J., Gruber, M. J., and Grossman, S. (1986). Discrete Expectational Data and Portfolio Performance. Journal of Finance, 41(3), 699-713.

Fama, E., and French, K. (1992), The Cross-Section of Expected Stock Returns, Journal of 
Finance, 47(2), 427-465

Fong, K., Gallagher, D. R., and Lee, A. D. (2008). Benchmarking benchmarks: measuring characteristic selectivity using portfolio holdings data. Accounting and Finance, 48(5), 761-781.

Gallagher, D. R., and Looi, A. (2006). Trading Behaviour and the Performance of Daily Institutional Trades. Accounting and Finance, 46(1), 125-147.

Gharghori, P., Chan, H., and R. Faff (2007). Are the Fama-French Factors Proxying Default Risk? Australian Journal of Management, 32(2), 223-249.

Grinblatt, M., and Titman, S. (1993). Performance Measurement without Benchmarks: An Examination of Mutual Fund Returns. Journal of Business, 66(1), 47-68.

Irvine, P., Lipson, M., and Puckett, A. (2007). Tipping. Review of Financial Studies, 20(3), 741768.

Irvine, P. J. (2003). The Incremental Impact of Analyst Initiation of Coverage. Journal of Corporate Finance, 9, 431-451.

Jegadeesh, N., Joonghyuk, K., Krische, S. D., and Lee, C. M. C. (2004). Analyzing the Analysts: When Do Recommendations Add Value? Journal of Finance, 59(3), 1083-1124.

Jensen, M. C. (1968). The Performance of Mutual Funds in the Period 1945-1964. Journal of Finance, 23(2), 389-416.

Kecskes, A., and Womack, K. L. (2007). Adds and Drops of Analyst Coverage: Does the Stock Market Overreact? Working Paper.

Kelly, B. T., and Ljungqvist, A. (2007). The Value of Research. Working Paper.

Kothari, S., and Warner, J. (2006). Econometrics of Event Studies. In Espen Eckbo, Ed. Handbook of Empirical Corporate Finance, Elsevier-North-Holland.

Kothari, S. P., and Warner, J. B. (2001). Evaluating Mutual Fund Performance. Journal of Finance, 56(5), 1985-2010.

Lehmann, B. N., and Modest, D. M. (1987). Mutual Fund Performance Evaluation: A Comparison of Benchmarks and Benchmark Comparisons. Journal of Finance, 42(2), 233-265.

MacKinlay, A. C. (1997). Event Studies in Economics and Finance. Journal of Economic Literature, 35(1), 13-39.

Newey, W. K., and West, K. D. (1987). A Simple, Positive Semi-Definite, Heteroskedasticity and Autocorrelation Consistent Covariance Matrix. Econometrica, 55(3), 703-708.

Petersen, M. A. (2009). Estimating Standard Errors in Finance Data Sets: Comparing Approaches. Review of Financial Studies, 22(1), 435-480.

Pinnuck, M. (2003). An Examination of the Performance of the Trades and Stock Holdings of Fund Managers: Further Evidence. Journal of Financial and Quantitative Analysis, 38(4), 811828.

Saar, G. (2001). Price Impact Asymmetry of Block Trades: An Institutional Trading Explanation. Review of Financial Studies, 14(4), 1153-1181.

Stickel, S. (1995). The Anatomy of the Performance of Buy and Sell Recommendations. Financial Analysts Journal, 51(5), 25-39.

Womack, K. L. (1996). Do Brokerage Analysts' Recommendations Have Investment Value? Journal of Finance, 51(1), 137-167. 


\section{Table 1 - Summary Statistics for Transactions Data - Full Sample}

Trade packages are defined as a fund manager's successive trades in a particular stock within the same direction (i.e., only a buy or sell in one package) until no trades are executed for a period of five consecutive days. Panel A reports summary statistics for all buy trade packages, with a breakdown for the number of days it took to execute the entire trade package. Panel B reports summary statistics for sell trade packages with a similar breakdown. The sample is also split into quartiles based on trade package value.

\begin{tabular}{|c|c|c|c|c|c|}
\hline \multicolumn{6}{|c|}{ Summary Statistics for Trade Packages Full Sample - February 1997 to June 2004} \\
\hline \multicolumn{6}{|c|}{ Panel A: Buys } \\
\hline & 1 day & 2-4 days & 5-8 days & $>8$ days & Total buy packs \\
\hline Number of packages & 4,452 & 1,984 & 1,206 & 883 & 8,525 \\
\hline$\%$ of buys & 52 & 23 & 14 & 10 & 100 \\
\hline Mean pack value $\$$ & 201,480 & 321,056 & 497,848 & $1,088,375$ & 363,097 \\
\hline Std dev pack value & 390,549 & 452,681 & 602,517 & $1,258,422$ & 643,128 \\
\hline Q1 & 35,844 & 94,242 & 150,449 & 308,446 & 60,789 \\
\hline Median & 92,428 & 186,114 & 313,254 & 640,422 & 159,540 \\
\hline Q3 & 202,500 & 371,431 & 581,005 & $1,370,171$ & 385,700 \\
\hline \multicolumn{6}{|c|}{ Panel B: Sells } \\
\hline & 1 day & $2-5$ days & 5-8 days & $>8$ days & Total sell packs \\
\hline Number of packages & 3,336 & 1,633 & 844 & 722 & 6,535 \\
\hline$\%$ of sells & 51 & 25 & 13 & 11 & 100 \\
\hline Mean pack value $\$$ & 227,940 & 339,028 & 505,967 & 895,512 & 365,361 \\
\hline Std dev pack value & 488,489 & 563,481 & 639,539 & $1,140,198$ & 663,890 \\
\hline Q1 & 35,866 & 71,589 & 117,374 & 241,349 & 59,409 \\
\hline Median & 107,128 & 167,538 & 290,685 & 548,596 & 156,860 \\
\hline Q3 & 238,354 & 363,440 & 658,340 & $1,099,648$ & 389,961 \\
\hline
\end{tabular}


Table 2 - Returns around Recommendation Date - Market Model Cumulative Abnormal Returns (CARs)

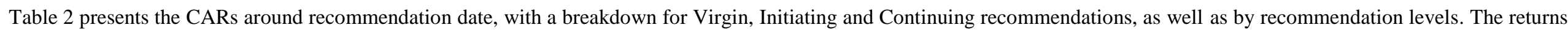

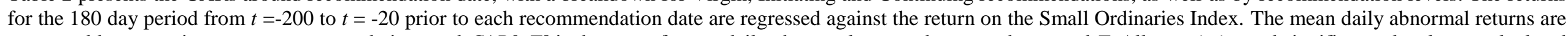

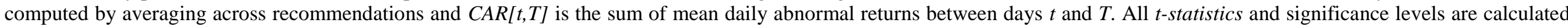
using Newey West (1987) standard errors which adjust for heteroskedasticity and autocorrelation in the residuals.

\begin{tabular}{|c|c|c|c|c|c|c|c|c|c|c|c|}
\hline \multicolumn{4}{|c|}{ Panel A: Virgin recommendations } & \multicolumn{4}{|c|}{ Panel B: Initiating recommendations } & \multicolumn{4}{|c|}{ Panel C: Continuing recommendations } \\
\hline Event & $\begin{array}{l}\text { Strong } \\
\text { Buy/Buy }\end{array}$ & Hold & Underperform/Sell & Event & $\begin{array}{l}\text { Strong } \\
\text { Buy/Buy }\end{array}$ & Hold & Underperform/Sell & Event & $\begin{array}{l}\text { Strong } \\
\text { Buy/Buy }\end{array}$ & Hold & Underperform/Sell \\
\hline CAR $[-10 ; 0]$ & 0.0108 & -0.0074 & -0.0158 & CAR $[-10 ; 0]$ & -0.0014 & -0.0004 & $-0.0084^{*}$ & CAR $[-10 ; 0]$ & $0.0026 * *$ & -0.0022 & $-0.0160 * * *$ \\
\hline CAR $[-9 ; 0]$ & 0.0098 & -0.0095 & -0.0102 & CAR $[-9 ; 0]$ & -0.0016 & 0.0002 & -0.0068 & CAR $[-9 ; 0]$ & $0.0029 * *$ & $-0.0023^{*}$ & $-0.0160 * * *$ \\
\hline CAR $[-8 ; 0]$ & 0.0101 & -0.0083 & -0.0090 & CAR $[-8 ; 0]$ & -0.0013 & 0.0006 & -0.0056 & CAR[-8;0] & $0.0035^{* * *}$ & $-0.0023^{*}$ & $-0.0163 * * *$ \\
\hline CAR $[-7 ; 0]$ & 0.0106 & -0.0064 & -0.0071 & CAR $[-7 ; 0]$ & -0.0011 & 0.0000 & -0.0043 & CAR $[-7 ; 0]$ & $0.0045 * * *$ & $-0.0024 *$ & $-0.0164 * * *$ \\
\hline CAR[-6;0] & 0.0106 & -0.0056 & -0.006 & CAR $[-6 ; 0]$ & -0.0016 & 0.0004 & -0.0024 & CAR[-6;0] & $0.0050 * * *$ & -0.0016 & $-0.0168 * * *$ \\
\hline CAR $[-5 ; 0]$ & 0.0051 & -0.0037 & 0.0034 & CAR $[-5 ; 0]$ & -0.0007 & 0.0006 & -0.0027 & CAR $[-5 ; 0]$ & $0.0052 * * *$ & -0.0018 & $-0.0157 * * *$ \\
\hline CAR $[-4 ; 0]$ & 0.0006 & -0.0015 & 0.0076 & CAR $[-4 ; 0]$ & 0.0002 & 0.0006 & $-0.0041 *$ & CAR $[-4 ; 0]$ & $0.0047 * * *$ & $-0.0023 * *$ & $-0.0151 * * *$ \\
\hline CAR $[-3 ; 0]$ & 0.0016 & 0.0014 & 0.0018 & CAR $[-3 ; 0]$ & 0.0003 & 0.0000 & -0.0037 & CAR $[-3 ; 0]$ & $0.0043 * * *$ & $-0.0020 * *$ & $-0.0118 * * *$ \\
\hline CAR $[-2 ; 0]$ & 0.0061 & -0.0026 & -0.0033 & CAR $[-2 ; 0]$ & 0.0012 & -0.0002 & -0.0028 & CAR[-2;0] & $0.0032 * * *$ & $-0.0013 *$ & $-0.0087 * * *$ \\
\hline CAR $[-1 ; 0]$ & 0.002 & -0.0003 & -0.0024 & CAR $[-1 ; 0]$ & 0.0003 & -0.0001 & $-0.0021 *$ & CAR $[-1 ; 0]$ & $0.0027 * * *$ & $-0.0011 * *$ & $-0.0041 * * *$ \\
\hline $\mathrm{CAR}[0 ;+1]$ & -0.0004 & 0.0021 & 0.0018 & CAR $[0 ;+1]$ & $0.0011 *$ & $-0.0017 * *$ & 0.0021 & CAR $[0 ;+1]$ & $0.0014 * * *$ & $-0.0013 * * *$ & $-0.0038 * * *$ \\
\hline $\mathrm{CAR}[0 ;+2]$ & 0.0013 & 0.0002 & -0.0023 & CAR $[0 ;+2]$ & 0.0013 & $-0.0021 * *$ & 0.0008 & CAR $[0 ;+2]$ & $0.0023 * * *$ & $-0.0025 * * *$ & $-0.0060 * * *$ \\
\hline CAR $[0 ;+3]$ & -0.0059 & 0.0036 & 0.0051 & CAR $[0 ;+3]$ & 0.0008 & $-0.0033 * * *$ & -0.0011 & CAR $[0 ;+3]$ & $0.0034 * * *$ & $-0.0029 * * *$ & $-0.0064 * * *$ \\
\hline CAR $[0 ;+4]$ & $-0.0133 * * *$ & 0.0007 & 0.0105 & CAR $[0 ;+4]$ & -0.0011 & $-0.0050 * * *$ & -0.0035 & CAR $[0 ;+4]$ & $0.0033 * * *$ & $-0.0032 * * *$ & $-0.0074 * * *$ \\
\hline CAR $[0 ;+5]$ & $-0.0108 * *$ & 0.0035 & 0.0081 & CAR $[0 ;+5]$ & -0.0004 & $-0.0062 * * *$ & -0.0042 & CAR $[0 ;+5]$ & $0.0030 * * *$ & $-0.0037 * * *$ & $-0.0085 * * *$ \\
\hline CAR $[0 ;+6]$ & $-0.0140 * *$ & 0.0016 & 0.0221 & $\operatorname{CAR}[0 ;+6]$ & -0.0009 & $-0.0059 * * *$ & $-0.0080 * *$ & CAR $[0 ;+6]$ & $0.0036 * * *$ & $-0.0041 * * *$ & $-0.0090 * * *$ \\
\hline $\mathrm{CAR}[0 ;+7]$ & -0.0118 & 0.0015 & 0.0171 & CAR $[0 ;+7]$ & -0.0014 & $-0.0062 * * *$ & $-0.0100 * *$ & CAR $[0 ;+7]$ & $0.0036 * * *$ & $-0.0042 * * *$ & $-0.0097 * * *$ \\
\hline $\mathrm{CAR}[0 ;+8]$ & $-0.0130 *$ & 0.0040 & 0.0052 & CAR $[0 ;+8]$ & -0.0025 & $-0.0063 * * *$ & $-0.0093 * *$ & CAR $[0 ;+8]$ & $0.0032 * * *$ & $-0.0041 * * *$ & $-0.0099 * * *$ \\
\hline CAR $[0 ;+9]$ & $-0.0143 *$ & 0.0024 & 0.0075 & CAR $[0 ;+9]$ & $-0.0034 *$ & $-0.0067 * * *$ & $-0.0100 * *$ & CAR $[0 ;+9]$ & $0.0034 * * *$ & $-0.0044 * * *$ & $-0.0108 * * *$ \\
\hline CAR $[0 ;+10]$ & $-0.0155^{*}$ & 0.0048 & 0.0103 & CAR $[0 ;+10]$ & $-0.0038 *$ & $-0.0074 * * *$ & $-0.0129 * * *$ & $\mathrm{CAR}[0 ;+10]$ & $0.0036 * * *$ & $-0.0049 * * *$ & $-0.0109 * * *$ \\
\hline
\end{tabular}

***, ** and * indicates significance at the $1 \%, 5 \%$ and $10 \%$ (two-tail) level, respectively. $\mathrm{H}_{0}: C A R[t, T]=0$ and $\mathrm{H}_{1}: C A R[t, T] \neq 0$. 


\section{Table 3 - Returns-Based Performance Measures - Multi-Factor Models}

Table 3 presents the results derived from returns-based models, where $b$ 's represent the loading coefficient on their corresponding factor. The results for a single-factor model are presented in Panel A, Panel B reports the results derived from a three-factor Fama-French (1992) model, Panel C reports results derived from a fourfactor Carhart (1997) model, Panel D reports results derived from our five-factor Broker Recommendation model, specified as follows;

$r_{i, t}=a_{i}+b_{i S O} r_{m, t}+b_{i H M L_{t}} H M L_{t}+b_{i S M B} S M B_{t}+b_{i P R 1 Y R} P R I Y R_{t}+b_{i B M S} B M S_{t}+e_{i, t}$

T-tests: H0 coefficient $=0$. All t-statistics and significance levels are calculated using Newey West (1987) standard errors which adjust for heteroskedasticity and autocorrelation in the residuals of panel data. Note: Alpha estimates are reported in decimal form.

\begin{tabular}{|c|c|c|c|c|c|c|c|}
\hline \multicolumn{8}{|c|}{ Returns-based performance evaluation - Multi-Factor Models - March 1995 to March 2004} \\
\hline & Mean & Median & Min & $\operatorname{Max}$ & Std. Dev. & Pos. Sig. & Neg Sig. \\
\hline \multicolumn{8}{|c|}{ Panel A: Single Factor Model (Jensen's Alpha) } \\
\hline$\alpha$ & 0.0082 & 0.0072 & -0.0025 & 0.0260 & 0.0063 & $8 * * *$ & 0 \\
\hline$\beta S O$ & 0.8669 & 0.8450 & 0.5516 & 1.4315 & 0.2081 & 14 & 0 \\
\hline Adjusted R-squared & 0.7068 & 0.6986 & 0.3527 & 0.9371 & 0.1547 & & \\
\hline Number of Months & 50.6429 & 38 & 13 & 114 & 33.9652 & & \\
\hline \multicolumn{8}{|c|}{ Panel B: Three-Factor Model (Fama French 1992) } \\
\hline$\alpha$ & 0.0069 & 0.0075 & -0.0044 & 0.0209 & 0.0069 & $6 * * *$ & 0 \\
\hline$\beta_{\mathrm{SO}}$ & 0.8465 & 0.8478 & 0.5105 & 1.3616 & 0.1982 & 14 & 0 \\
\hline$\beta_{\mathrm{HML}}$ & 0.0595 & -0.0058 & -0.1271 & 0.6764 & 0.2186 & 3 & 0 \\
\hline$\beta_{\mathrm{SMB}}$ & 0.0301 & 0.0077 & -0.0808 & 0.2360 & 0.1033 & 3 & 1 \\
\hline Adjusted R-squared & 0.7098 & 0.6979 & 0.4037 & 0.9529 & 0.1525 & & \\
\hline Number of Months & 50.6429 & 38 & 13 & 114 & 33.9652 & & \\
\hline \multicolumn{8}{|c|}{ Panel C: Four-Factor Model (Carhart 1997) } \\
\hline$\alpha$ & 0.0058 & 0.0052 & -0.005 & 0.0189 & 0.0064 & $6 * * *$ & 0 \\
\hline$\beta_{\text {SO }}$ & 0.8781 & 0.8572 & 0.5129 & 1.3617 & 0.2133 & 14 & 0 \\
\hline$\beta_{\mathrm{HML}}$ & 0.0556 & -0.0051 & -0.13 & 0.6848 & 0.2147 & 2 & 0 \\
\hline$\beta_{\mathrm{SMB}}$ & 0.0977 & 0.0928 & -0.071 & 0.3617 & 0.1317 & 4 & 1 \\
\hline$\beta_{\mathrm{MOM}}$ & 0.1003 & 0.0501 & -0.0588 & 0.3909 & 0.1355 & 3 & 0 \\
\hline Adjusted R-squared & 0.7185 & 0.7179 & 0.3555 & 0.9517 & 0.1671 & & \\
\hline Number of Months & 50.6429 & 38 & 13 & 114 & 33.9652 & & \\
\hline \multicolumn{8}{|c|}{ Panel D: Five-Factor Model } \\
\hline$\alpha$ & 0.0054 & 0.0050 & -0.0135 & 0.0172 & 0.0072 & $5 * * *$ & 0 \\
\hline$\beta_{\mathrm{SO}}$ & 0.8132 & 0.7648 & 0.4934 & 1.2704 & 0.2375 & 13 & 0 \\
\hline$\beta_{\mathrm{HML}}$ & 0.0737 & 0.0526 & -0.123 & 0.7286 & 0.2233 & 2 & 0 \\
\hline$\beta_{\mathrm{SMB}}$ & 0.1133 & 0.1146 & -0.0609 & 0.3875 & 0.1365 & 5 & 1 \\
\hline$\beta_{\mathrm{MOM}}$ & 0.1108 & 0.0705 & -0.0516 & 0.3849 & 0.1285 & 3 & 0 \\
\hline$\beta_{\mathrm{BMS}}$ & 0.0791 & 0.1403 & -0.8183 & 0.6962 & 0.3425 & 3 & 0 \\
\hline Adjusted R-squared & 0.7223 & 0.7178 & 0.4044 & 0.9518 & 0.1612 & & \\
\hline Number of Months & 50.6429 & 38 & 13 & 114 & 33.9652 & & \\
\hline
\end{tabular}


Table 4 - Results from Transaction-Based Measures - CARs around Transactions

Table 4 presents cumulative abnormal returns calculated using the last day of the trade package as the reference date. Abnormal returns are computed based on DGTW-adjusted daily alphas and the mean daily abnormal return and cumulative abnormal returns are then computed.

All $t$-statistics and significance levels are calculated using Newey West (1987) standard errors which adjust for heteroskedasticity and autocorrelation in the residuals of panel data.

\begin{tabular}{|c|c|c|c|c|}
\hline \multicolumn{5}{|c|}{ Transaction-Based Performance Measures - February 1997 to June 2004} \\
\hline \multicolumn{5}{|c|}{ CARs around Transactions by Recommendation Level and Trade Type } \\
\hline & \multicolumn{2}{|c|}{ Buy Pack } & \multicolumn{2}{|c|}{ Sell Pack } \\
\hline Event day & Buy & Sell & Buy & Sell \\
\hline $\mathrm{N}$ & 1248 & 324 & 1003 & 225 \\
\hline \multirow[t]{2}{*}{ CAR[-60;0] } & $0.0437 * * *$ & $0.0355 * * *$ & $0.0389 * * *$ & 0.0085 \\
\hline & $(0.0069)$ & $(0.0096)$ & $(0.0079)$ & $(0.0106)$ \\
\hline \multirow[t]{2}{*}{ CAR $[-50 ; 0]$} & $0.0351 * * *$ & $0.0261 * * *$ & $0.0296 * * *$ & 0.0058 \\
\hline & $(0.0058)$ & $(0.0094)$ & $(0.0069)$ & $(0.0108)$ \\
\hline \multirow[t]{2}{*}{ CAR $[-40 ; 0]$} & $0.0276^{* * * *}$ & $0.0193 * *$ & $0.0261 * * *$ & -0.0060 \\
\hline & $(0.0050)$ & $(0.0086)$ & $(0.0056)$ & $(0.0088)$ \\
\hline \multirow[t]{2}{*}{ CAR $[-30 ; 0]$} & $0.0196^{* * * *}$ & 0.0115 & $0.0152 * * *$ & -0.0050 \\
\hline & $(0.0042)$ & $(0.0074)$ & $(0.0044)$ & $(0.0082)$ \\
\hline \multirow[t]{2}{*}{ CAR[-20;0] } & $0.0097 * * *$ & $0.0126^{* *}$ & $0.0080 * *$ & -0.0097 \\
\hline & $(0.0031)$ & $(0.0054)$ & $(0.0034)$ & $(0.0068)$ \\
\hline \multirow[t]{2}{*}{ CAR $[-10 ; 0]$} & 0.0025 & 0.0029 & 0.0035 & 0.0013 \\
\hline & $(0.0022)$ & $(0.0032)$ & $(0.0023)$ & $(0.0031)$ \\
\hline \multirow[t]{2}{*}{ CAR $[0 ; 10]$} & $0.0045^{* * * *}$ & 0.0024 & $0.0072 * * *$ & -0.0021 \\
\hline & $(0.0017)$ & $(0.004)$ & $(0.0020)$ & $(0.0033)$ \\
\hline \multirow[t]{2}{*}{ CAR $[0 ; 20]$} & $0.0055^{* *}$ & -0.0031 & $0.0059 * *$ & 0.0026 \\
\hline & $(0.0024)$ & $(0.0044)$ & $(0.0029)$ & $(0.0058)$ \\
\hline \multirow[t]{2}{*}{ CAR $[0 ; 30]$} & 0.0051 & -0.0008 & 0.0032 & 0.0033 \\
\hline & $(0.0033)$ & $(0.0051)$ & $(0.0036)$ & $(0.0072)$ \\
\hline \multirow[t]{2}{*}{ CAR $[0 ; 40]$} & $0.0091 * *$ & 0.0020 & 0.0012 & 0.0063 \\
\hline & $(0.0040)$ & $(0.0061)$ & $(0.0042)$ & $(0.0082)$ \\
\hline \multirow[t]{2}{*}{ CAR $[0 ; 50]$} & $0.0121 * * *$ & 0.0089 & 0.0027 & 0.0030 \\
\hline & $(0.0046)$ & $(0.0071)$ & $(0.0046)$ & $(0.0092)$ \\
\hline \multirow[t]{2}{*}{ CAR $[0 ; 60]$} & $0.0156 * * *$ & 0.0082 & 0.0025 & 0.0047 \\
\hline & $(0.0052)$ & $(0.0076)$ & $(0.0053)$ & $(0.0096)$ \\
\hline
\end{tabular}

***, ** and * indicates significance at the $1 \%, 5 \%$ and $10 \%$ (two-tail) level, respectively, based on T-tests 


\section{Table 5 - Results from Transaction-Based Performance Measures}

Table 5 presents descriptive statistics of the trade-related metrics used in analysing transaction-based performance. The mean transaction weight is total value of the trade package divided by the fund's Net Asset Value $(N A V)$, averaged across number of trade packages. This can be expressed as;

$$
\text { TransactionWeight }_{i j t}=\frac{\text { TradePackageValue }_{i j t}}{N A V_{j t}}
$$

where $N$ is the number of trade packages, $L$ is the total number of managers, $N A V_{j t}$ is fund $j$ 's $N A V$ in time $t$, Trade Package Value $i t j$ is the dollar value of the trade package $i$ made by fund $j$ at time $t$.

Relative Position (Prior) to trade is defined as a fund's holding in a stock in the prior month as a proportion of $N A V$ in the current month. This is expressed as;

$$
\text { RelativePosition }(\text { Prior })_{i j t}=\frac{\text { HoldingValue }_{i j t-1}}{N A V j t}
$$

Similarly, Relative Position (Post) trade is defined as the sum of a fund's existing holding in a stock and the trade package value as a proportion of $N A V$. This is expressed as;

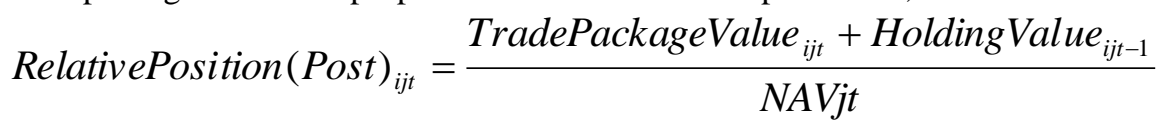

Overweight relative to index is weight of the stock underlying trade package $i$ within the Small Ordinaries Index subtracted from Relative Position (Post) computed as per Equation (5).

\begin{tabular}{|c|c|c|c|c|}
\hline \multicolumn{5}{|c|}{ Transaction-Based Performance Measures - February 1997 to June 2004} \\
\hline \multicolumn{5}{|c|}{ Panel A: All trade packages in recommendation subsample } \\
\hline & \multicolumn{2}{|c|}{ Buy Transactions } & \multicolumn{2}{|c|}{ Sell Transactions } \\
\hline Recommendation Level & Strong Buy/Buy & Underperform/Sell & Strong Buy/Buy & Underperform/Sell \\
\hline $\mathrm{N}$ & 1,111 & 302 & 854 & 190 \\
\hline $\mathrm{N}$ with existing stock position & 948 & 272 & 823 & 187 \\
\hline $\begin{array}{l}\% \text { transactions with existing } \\
\text { position }\end{array}$ & 85.33 & 90.07 & 96.37 & 98.42 \\
\hline Mean trade package size $\$$ & 344,624 & 249,453 & 325,623 & 313,774 \\
\hline $\begin{array}{l}\text { Mean Transaction weight } \\
\text { (\% NAV) }\end{array}$ & 0.43 & 0.32 & 0.34 & 0.28 \\
\hline $\begin{array}{l}\text { Relative position - Prior to } \\
\text { Trade (\% NAV) }\end{array}$ & 1.55 & 1.63 & 2.16 & 2.03 \\
\hline $\begin{array}{l}\text { Relative position - Post Trade } \\
\text { (\%NAV) }\end{array}$ & 1.98 & 1.95 & 1.82 & 1.75 \\
\hline $\begin{array}{l}\text { Overweight Relative to Index } \\
\text { - post-trade position }\end{array}$ & 1.03 & 0.87 & 0.87 & 0.73 \\
\hline
\end{tabular}

Overweight $_{i j t}=$ RelativePosition $\left._{(\text {Post }}\right)_{i j t}-$ Weight $_{i t X S O}$ 


\section{Table 6 - Coverage Levels and Transaction-Based Performance}

Table 6 (Panel A) presents the CARs from the last day of a buy trade package, with a split around broker coverage levels. $N$ refers to the total number of brokers following the underlying stock of a particular trade package, defined as number of unique brokers who have issued a recommendation within the same year. Similarly, Panel B presents the results for sell packs. Abnormal returns are computed based on DGTWadjusted daily alphas. The mean daily abnormal return and cumulative abnormal returns between day $t$ and $T$, denoted as CAR $[t, T]$, are computed by summing the mean daily abnormal returns from days $t$ to $T$.

All $t$-statistics and significance levels are calculated using Newey West (1987) standard errors which adjust for heteroskedasticity and autocorrelation in the residuals of panel data.

\begin{tabular}{|c|c|c|c|c|c|}
\hline \multicolumn{6}{|c|}{ Transaction-based performance by Coverage Level - February 1997 to June 2004} \\
\hline \multicolumn{6}{|c|}{ Panel A - Transaction-based CARs by Coverage Level for Buy Packs } \\
\hline Trade type & & & Buy Packs & & \\
\hline Coverage level (no. of brokers) & 0 & 1 to 3 & 4 to 6 & 7 to 9 & $>9$ \\
\hline $\mathrm{N}$ & 559 & 1596 & 2107 & 1371 & 101 \\
\hline CAR $[-60 ; 0]$ & $0.0486 * * *$ & $0.0269 * * *$ & $0.0274 * * *$ & $0.0215 * * *$ & $0.0466 * *$ \\
\hline CAR[-30;0] & $0.0253 * * *$ & $0.0117 * *$ & $0.0089 * * *$ & $0.0090 *$ & $0.0307 *$ \\
\hline CAR $[-10 ; 0]$ & 0.0032 & 0.0020 & -0.0013 & -0.0005 & 0.0074 \\
\hline CAR $[0 ; 10]$ & 0.0013 & 0.0009 & $0.0064 * * *$ & 0.0024 & 0.0040 \\
\hline CAR $[0 ; 30]$ & 0.0071 & -0.0049 & $0.0088^{* * *}$ & 0.0042 & 0.0081 \\
\hline CAR $[0 ; 60]$ & 0.0044 & -0.0062 & $0.0141 * * *$ & $0.0126 *$ & $0.0428 * *$ \\
\hline \multicolumn{6}{|c|}{ Panel B - Transaction-based CARs by Coverage Level for Sell Packs } \\
\hline Trade type & & & Sell Packs & & \\
\hline Coverage level (no. of brokers) & 0 & 1 to 3 & 4 to 6 & 7 to 9 & $>9$ \\
\hline $\mathrm{N}$ & 356 & 1139 & 1686 & 1106 & 106 \\
\hline CAR $[-60 ; 0]$ & 0.0163 & 0.0119 & $0.0197 * * *$ & -0.0019 & 0.0217 \\
\hline CAR $[-30 ; 0]$ & -0.0098 & 0.0024 & $0.0064 *$ & -0.0024 & 0.0204 \\
\hline CAR $[-10 ; 0]$ & 0.0018 & 0.0049 & 0.0000 & -0.0007 & $0.0171 * * *$ \\
\hline CAR $[0 ; 10]$ & -0.0023 & -0.0034 & $0.0030 *$ & 0.0015 & 0.0042 \\
\hline CAR $[0 ; 30]$ & -0.0038 & -0.0092 & 0.0044 & -0.0020 & -0.0022 \\
\hline CAR $[0 ; 60]$ & $-0.0264 *$ & -0.0113 & 0.0047 & 0.0026 & 0.0099 \\
\hline
\end{tabular}

